\title{
Comentário ao Estudo "Competência Cultural na Intervenção com Imigrantes: Uma Análise Comparativa Entre Profissionais de Saúde, da Área Social e Polícias"
}

\author{
Comment to the Paper "Cultural Competence in \\ Intervention with Immigrants: A Comparative Analysis \\ Between Health Professionals, Social Workers and Police \\ Officers"
}

Fernando Luís MACHADO $\square^{1}$

Acta Med Port 2016 Oct;29(10):579-580 - http://dx.doi.org/10.20344/amp.8257

Palavras-chave: Atitude do Pessoal de Saúde; Competência Cultural; Conhecimentos, Atitudes e Prática em Saúde; Emigrantes e Imigrantes.

Keywords: Attitude of Health Personnel; Cultural Competency; Emigrants and Immigrants; Health Knowledge, Attitudes, Practice.

A chegada e fixação de muitos milhões de imigrantes das mais variadas proveniências, sobretudo desde os anos 60 do século passado, embora com calendários diversos consoante os países, significou um grande aumento da diversidade cultural na Europa. Ao mesmo tempo, colocou as questões da etnicidade, do multiculturalismo e da integração desses imigrantes no centro das preocupações dos estados recetores e das populações autóctones.

É importante recordar que estes imigrantes chegaram à Europa para trabalhar porque as reservas europeias de mão-de-obra eram insuficientes para as necessidades de economias que, durante algumas décadas, cresceram a taxas elevadas. A expressão 'pedimos braços, vieram homens' costuma ser usada para dizer que os milhões de pessoas que a Europa recebeu para responder às suas necessidades de mão-de-obra e que, ao mesmo tempo, desejavam sair dos seus países à procura de uma vida melhor, não eram só trabalhadores. Eram pessoas inteiras, que necessariamente iriam relacionar-se com todas as instituições da sociedade de acolhimento e não apenas com o mercado de trabalho. As instituições de ensino, de saúde, de apoio social, as autoridades policiais e de justiça, as instituições políticas, entre outras, são também interpeladas pela imigração.

Com a crise económico-financeira global iniciada em 2008, a entrada de novos migrantes laborais reduziu-se muito, uma vez que as economias europeias estagnaram e o desemprego aumentou. A Europa confronta-se agora com outro tipo de fluxos de pessoas, nomeadamente os refugiados de guerra oriundos do Médio Oriente, para os quais tardam, aliás, as soluções de acolhimento e que farão também aumentar a diversidade cultural nos países onde vierem a ser recebidos.

Mas se as crises de refugiados são conjunturais, dependendo de eventos que não têm um padrão previsível, já as carências de mão-de-obra de uma Europa envelhecida são de natureza estrutural e estão bem identificadas. Assim que as economias forem reanimando, mesmo que não voltem às altas taxas de crescimento de outros tempos, mais imigrantes laborais chegarão.

Na primeira linha do trabalho de gestão da diversidade cultural e da integração dos imigrantes estão, entre outras, as instituições de saúde, de apoio social e as autoridades policiais, justamente aquelas cujos profissionais foram objeto de inquérito no estudo "Competência cultural na intervenção com imigrantes: Uma análise comparativa entre profissionais de saúde, da área social e polícias" agora publicado. $^{1}$

A literatura produzida em Portugal sobre processos de integração de imigrantes, questões de multiculturalismo e diversidade cultural é vasta, mas, surpreendentemente, são muito poucos os estudos que, como este, procurem saber junto de profissionais de setores que têm um contacto quotidiano de primeira linha com imigrantes em que medida se sentem qualificados para esse contacto.

Este é o primeiro mérito do estudo. Explora terrenos pouco conhecidos e, na medida em que o faz transversalmente em instituições de vários setores, podemos considerá-lo um estudo pioneiro. O segundo mérito é o facto de privilegiar uma abordagem comparativa. O mesmo instrumento de pesquisa empírica, um inquérito por questionário, foi aplicado a três grupos profissionais diferentes - profissionais de saúde, trabalhadores sociais e profissionais das polícias - e isso permite saber o que há de comum e de diferente entre eles no que se refere às competências de que dispõem para se relacionarem proficuamente com imigrantes no exercício das suas funções e em que medida essas diferenças e semelhanças estão relacionadas com a natureza das instituições onde trabalham. O terceiro mérito é a dimensão e a abrangência territorial da amostra em

1. ISCTE - Instituto Universitário de Lisboa. Lisboa. Portugal.

$\square$ Autor correspondente: Fernando Luís Machado. fernando.machado@iscte.pt

Recebido: 27 de setembro de 2016 - Aceite: 29 de setembro de 2016 | Copyright @ Ordem dos Médicos 2016 
que o estudo se baseia. No conjunto foram inquiridas mais de 600 pessoas, do continente e das regiões autónomas, distribuídas de maneira equilibrada pelos três grupos profissionais.

Estando em análise as competências culturais que estes grupos profissionais têm para lidar com populações imigrantes etnicamente diferenciadas, o estudo dirige-se, em particular, às competências percebidas pelos próprios profissionais, colocados assim numa posição de autoavaliação. Para o mesmo tema também seria possível desenhar pesquisas que visassem captar a avaliação que os próprios imigrantes fazem sobre a competência cultural destes profissionais ou ainda uma avaliação dessas competências feita por peritos em avaliação munidos dos instrumentos adequados.

Mas a autoavaliação é, sem dúvida, muito importante. Mesmo admitindo que uma parte dos inquiridos possa ter sobrestimado essas competências, dando as respostas que consideram socialmente desejáveis, o inquérito conduziu-os a pronunciarem-se sobre diferentes aspetos dessas competências, o que faz, quase inevitavelmente, com que as autoavaliações variem de um aspeto para outro. A identificação e análise dessas variações, sejam as variações internas a cada grupo profissional sejam as variações entre grupos, dão-nos indicações valiosas.

De facto, o modelo de análise adotado no estudo é abrangente e decompõe o conceito de competência cultural em quatro dimensões: consciência cultural; conhecimento cultural; competência ou aptidão prática; apoio organizacional. No inquérito, traduzido e adaptado para a população portuguesa a partir da sua versão original em língua inglesa, cada uma das quatro dimensões do conceito de competência cultural é desdobrada, por sua vez, em vários itens, num total de 16 .

O estudo chega assim a um amplo conjunto de resultados de grande utilidade não só no plano académico, como no plano das políticas institucionais e da reflexão e ação dos profissionais que no seu dia-a-dia trabalham com populações etnicamente diferenciadas.

Os resultados mostram, por um lado, variações no modo

\section{REFERÊNCIAS}

1. Gonçalves M, Matos M. Competência cultural na intervenção com imigrantes: uma análise comparativa entre profissionais da saúde, da como os três grupos de profissionais avaliam a sua competência cultural em cada uma das dimensões em que esta se desdobra, sendo claro que há grupos que se consideram mais competentes numas dimensões e outros noutras. Os profissionais de apoio social, os profissionais das polícias e os profissionais de saúde não se consideram igualmente competentes em todas as dimensões avaliadas.

Por outro lado, mostram que fatores como o género, a idade, o tempo de serviço, a experiência mais ou menos longa de contacto com populações multiculturais e ainda, e especialmente relevante, o ter ou não recebido formação específica neste domínio, fazem variar significativamente os níveis percebidos de competência cultural. $E$ também aqui há diferenças significativas entre os três grupos de profissionais.

De modo indireto, esta pesquisa acaba igualmente por fornecer elementos de diagnóstico das necessidades das instituições em matéria de competência cultural e formula, a este propósito, duas recomendações. Uma é o investimento em mais formação, seja nos currículos académicos de base, seja ao nível da formação contínua e avançada. Outra, que remete para o plano organizacional, é que a temática da competência cultural seja inscrita na própria missão estratégica dos serviços públicos e nas suas políticas institucionais.

As instituições que operam nos vários domínios da vida coletiva deparam-se inevitavelmente com a diversidade cultural das populações oriundas da imigração e têm um papel decisivo nos processos de integração social dessas populações.

O papel dessas instituições é particularmente importante no caso dos segmentos de imigrantes mais vulneráveis, os que se encontram em situações de pobreza, os que chegaram há pouco tempo e decifram mal o que se passa à sua volta, os que não dominam a língua do país que os recebeu ou os que estão confinados aos bairros onde moram e têm pouco contacto com a sociedade mais ampla. Por isso os resultados do trabalho agora apresentado são de grande utilidade tanto para essas instituições e seus profissionais como para as próprias populações imigrantes.

área social e polícias. Acta Med Port. 2016;29:629-638. 